\title{
Dr. Ikkaku Ochi Collection
}

\section{Erhard Taverna}

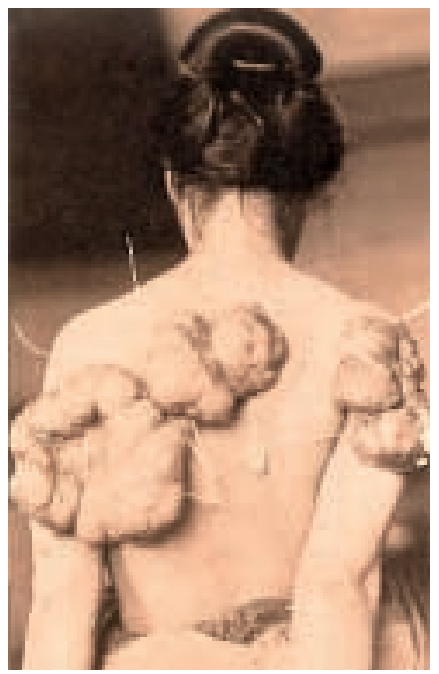

Ein Kunstsammler entdeckt zufällig eine Sammlung von Medizinfotografien im Lager eines Händlers. Auf deren Rückseite steht die Adresse eines Mannes, Ikkaku Ochi, Militärarzt, Internist in Hiroshima, gestorben 1930. Hergestellt wurden die Bilder Ende des 19. Jahrhunderts in einem Fotostudio im Auftrag des nahen Präfekturspitals und dessen medizinischer Fakultät. Nur von wenigen Patienten kennen wir die Krankengeschichte, ihr Bild wurde in Fachjournalen gezeigt und kommentiert. Die meisten der Glasplatten und Abzüge wurden im Herbst 2003 im Photomuseum Winterthur ausgestellt. Jetzt ist die Sammlung auch in Buchform einsehbar, und viele Darstellungen sind über Internetadressen zugänglich.

Es sind traurige Bilder von Männern, Frauen und Kindern, schwarzweiss und braun. Zerstörte Gesichter, deformierte Körper, weit fortgeschrittene Tumore, verrenkte Glieder, groteske Fehlstellungen, entstellende Narben, wuchernde Abszesse und Granulome. Darunter auch Embryonen, verstümmelte Neugeborene und zusammengewachsene Zwillinge. Eine Dokumentation zumeist hoffnungsloser Fälle, aufgenommen für Unterrichtszwecke, Forschungen und medizinische Publikationen. Nicht für eine Öffentlichkeit gedacht. Im Japan der Meiji-Ära (1868-1911) wurde viel fotografiert. Seit der durch amerikanische Kriegsschiffe erzwungenen Öffnung hatte sich die Insel tiefgreifend verändert. In allen Sparten der Technik und Medizin wetteiferte das Land mit der Wissenschaft und Technik des Westens.

Der Sammler und Galerist aus Tokio betont aus naheliegenden Gründen die Exotik des fernen Ostens. Die Fundschachtel aus leichtem Kaiserbaumholz, die stilvollen japanischen Schriftzeichen und den Geruch des in Zellophanpapier eingewickelten Bündels. Die Bilder erinnern ihn an Figuren des Kabuki-Theaters und an die traditionelle, japanische Ästhetik der Trauer. Verständlich, dass der Lehrbeauftragte für Medizingeschichte der Universität Okayama die 365 Aufnahmen mit den Präparatesammlungen europäischer Medizinhochschulen vergleicht und die Einzigartigkeit des Fundes hervorhebt.
Es ist nicht ganz einfach, die «traurige Schönheit der einfühlsamen Porträts vor dem folkloristischen Hintergrund» auszumachen, denen «mit Würde und Respekt» begegnet wurde. Das sind Behauptungen und Klischees, wie der beschworenen, Unterschied zu den «westlichen Abbildungen à la Pschyrembel». Wir können nur hoffen, dass die längst verstorbenen Akteure den Unglücklichen nicht nur ihr medizinisches Interesse, sondern tatsächlich auch Mitgefühl entgegenbrachten. Fachpersonen können sich emotional durch ihr Fachgebiet abschotten. Denn dem unerträglich Monströsen steht ein Helferkonzept entgegen. Was Ärztinnen und Ärzte sowie Laien teilen, ist die Scham, die in uns durch den inneren Konflikt der Neigungen und Hemmungen entsteht. Natürliche Neugier, Angst und Faszination gegen die anerzogene Rücksicht. Der entstellte Mensch schämt sich, weil er dem Blick des anderen ausgesetzt ist, der andere, weil ihn der Widerspruch seiner Gefühle blockiert. Alle schambesetzten Körperfunktionen, Entstellungen und Gewaltszenen machen aus uns rettungslos Voyeure. Die preisgekrönte Plakatkampagne zur Integration von Behinderten der Pro Infirmis 2002 wusste genau um diese Gefühlskollision. Sie zeigte darum Kinder auf dem Arm ihrer gesunden Eltern. Der beim Betrachter normalerweise vorhandene Schutzinstinkt erlaubt eine Orientierung angesichts des Schreckens. Erwachsenen können wir nicht auf die gleiche Art wie Kindern in die Augen sehen, das ist eine allgemeine Erfahrung.

Vom Tabu zum Tableau. Ob uns der Anblick der über 100jährigen Schmerzgalerie humaner macht, ist fraglich. Kollege Ikkaku Ochi hätte sich den Untergang von Hiroshima nie vorstellen können. Wir schon.

Akimitsu Naruyama (ed.). Dr. Ikkaku Ochi Collection. Zürich: Scalo 2004. Deutsch-Englisch, 215 Seiten. 